\title{
Curcumin enhances anti-cancer efficacy of either gemcitabine or docetaxel on pancreatic cancer cells
}

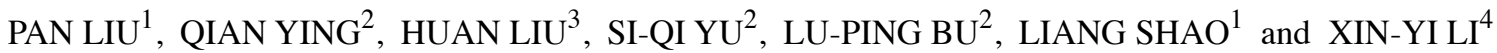 \\ ${ }^{1}$ Department of Hematology, Zhongnan Hospital of Wuhan University, Wuhan, Hubei 430071; ${ }^{2}$ Department of Immunology, \\ School of Basic Medical Sciences, Wuhan University, Wuhan, Hubei 430072; Departments of ${ }^{3}$ Pathology \\ and ${ }^{4}$ Anesthesiology, Zhongnan Hospital of Wuhan University, Wuhan, Hubei 430071, P.R. China
}

Received December 12, 2019; Accepted June 23, 2020

DOI: $10.3892 /$ or.2020.7713

\begin{abstract}
Curcumin is a natural compound extracted from turmeric (Curcuma longa), which has been reported to be a promising anti-cancer drug in various human cancers. However, the effects of combination treatment of curcumin with gemcitabine or docetaxel on pancreatic cancer remains elusive. In the present study, the combinatory effects of curcumin with either gemcitabine or docetaxel on the proliferation, apoptosis, migration as well as invasion of PC cells were investigated. Calcusyn software was used to determine whether curcumin has is synergistic with gemcitabine or docetaxel. Combination index values from combinational use were all lower than 1 , indicating the synergism of curcumin with gemcitabine or docetaxel on PC cells in vitro. EdU assay showed that curcumin could enhance the ability of gemcitabine or docetaxel to inhibit the proliferation of PC cells. Furthermore, the results from transmission electron microscope, DAPI staining experiments and western blot analysis revealed that curcumin may trigger apoptosis of PC cells via PARP/caspase-3 signaling pathway and reinforced pro-apoptotic ability of either gemcitabine or docetaxel. In addition, curcumin exhibited marked suppressive ability on metastasis of PC cells by wound healing and matrigel-transwell assay. Mechanistically, upregulation of TIMP1/TIMP2 with concomitant downregulation of $\mathrm{MMP} 2 / \mathrm{MMP} / \mathrm{N}$-cadherin proteins may be involved in this process. In conclusion, curcumin showed synergistic anti-cancer effects with either gemcitabine or docetaxel on PC cells.
\end{abstract}

\section{Introduction}

Pancreatic cancer (PC) is a lethal disease, which has a 5-year survival rate of $<7 \%$ (1). Although surgery has improved

Correspondence to: Dr Xin-Yi Li, Department of Anesthesiology, Zhongnan Hospital of Wuhan University, 169 Donghu Road, Wuhan, Hubei 430071, P.R. China

E-mail:wb002374@whu.edu.cn

Key words: pancreatic cancer, curcumin, combination index, gemcitabine, docetaxel, apoptosis, metastasis the overall survival (OS) of PC patients with early stage, the prognosis of the majority of late stage PC patients is extremely poor $(2,3)$. The recently recommended first-line chemotherapeutic regimen incorporating gemcitabine and paclitaxel for PC patients who are not eligible for surgery, could prolong the survival of PC patients. Gemcitabine is a deoxycytidine analogue widely used for the therapy of PC patients and improved their survival (4). Docetaxel, a semi-synthetic analogue of paclitaxel, is a clinically well used anti-mitotic chemotherapeutic drug for the treatment of various carcinomas, including breast, ovarian, lung and pancreatic cancer $(1,2,5)$. However, the unsatisfactory effects and unavoidable toxic side effects are major obstacles for the present chemotherapeutic regimens $(1,2,6)$. Therefore, these challenges highlight the importance of identifying an alternative therapy with satisfactory effects and decreasing the long-term toxic side effects.

Cell death forms include apoptosis and necrosis. Apoptosis depends on initiator caspases (such as caspase- 8 and -9) and executioner caspases (caspase-3, -6 and -7) (7). Chemotherapeutic drugs usually induce apoptosis of cancer cells through PARP-caspase3 pathway (8-10). Curcumin was considered a promising agent in treating various types of cancer by inducing apoptosis of cancer cells (11-13). To elucidate the mechanisms of curcumin inducing apoptosis on PC cells, we detected PARP-caspase 3 pathway on three types of cell lines.

Detached cancer cells are different from the normal cells undergoing anoikis after dropping off their primary site and this phenomenon is beneficial for metastasis $(14,15)$. Curcumin was reported to be able to enhance chemotherapeutic effects on anoikis-resistant cancer cells (16), which would suppress metastasis of cancer cells. Metastasis remains a serious problem affecting PC treatment efficiency, and metastasis prevention is a promising strategy for PC treatment and curcumin was found to be able to inhibit cancer metastasis (17-19). In the present study, the property of curcumin was found to suppress PC cell metastasis and potentiate anti-metastasis chemotherapeutic effects.

Curcumin, a hydrophobic polyphenol extracted from dried rhizomes of turmeric, is a kind of traditional Chinese herbal medicine and a potential drug for cancer therapy (20). A growing body of evidence has demonstrated that curcumin has 
a potent anti-cancer effect for PC treatment by inducing cell apoptosis, inhibiting cell proliferation, and suppressing cell migration and invasion of PC cells in pre-clinical studies (21). However, whether curcumin has synergistic effects with either gemcitabine or docetaxel for the treatment of PC remains elusive.

In the present study, we determined whether curcumin has a synergistic effect with gemcitabine or docetaxel on cell proliferation, apoptosis, migration, and invasion of PC cells. Furthermore, the possible underlying mechanisms of the combination treatment regimens were investigated. The results indicate that curcumin is a promising adjuvant with the capacity of improving the anti-cancer effects of either gemcitabine or docetaxel on PC cells in vitro.

\section{Materials and methods}

Cell lines and reagents. Human pancreatic cell lines PANC-1, HPAF-II and MIAPaCa-2 were purchased from the Chinese Academy of Life Science. DMEM culture medium and fetal bovine serum (FBS) were purchased from HyClone Laboratories Inc. and Gibco Company, respectively. Curcumin was purchased from Xinran Company. Gemcitabine and docetaxel were obtained from Sigma-Aldrich and dissolved in DMSO.

Cell culture. PANC-1, HPAF-II and MIAPaCa-2 cells were cultured in DMEM culture medium with $10 \%$ FBS and $1 \%$ penicillin and streptomycin in an incubator with $5 \% \mathrm{CO}_{2}$ at $37^{\circ} \mathrm{C}$. Drugs were given at the concentrations of 2, 5, 10, 20 and $50 \mu \mathrm{M}$ for $48 \mathrm{~h}$.

MTT assay. Drug sensitivity was detected using the MTT assay. Briefly, cells were collected and cultured overnight, followed by replenishment with fresh medium containing drugs and incubated at $37^{\circ} \mathrm{C}$ cell incubator with $5 \% \mathrm{CO}_{2}$ for $48 \mathrm{~h}$. A total volume of $20 \mu \mathrm{l}$ of MTT (Sigma-Aldrich) in PBS with the working concentration of $5 \mathrm{mg} / \mathrm{ml}$ was added to the wells at the indicated times. The wells were then incubated for an additional $4 \mathrm{~h}$ at room temperature. The supernatant was discarded. A total volume of $100 \mu \mathrm{l}$ of DMSO was added to the wells, followed by measurement using a PerkinElmer 2030 VICTOR X Multilabel Plate Reader (Perkin-Elmer). The results were collected from three independent experiments. The percentage of live cells was represented as cell viability $(\%)=(\mathrm{OD}$ of treatment/OD of control) $x 100$. Three experimental repeats were carried out to calculate cell viability. The average values of 50\% inhibiting concentration (IC50) of curcumin in PANC-1, MIAPaca-2 and HPAF-II were calculated from the viability values.

Analysis of cytotoxic synergy. The cell viability of PANC-1, HPAF-II and MIAPaCa-2 cells were determined by MTT assay. The CI values were then calculated using Calcusyn 2.0 software. In detail, CI was detected using the equation: (D) $1 /(\mathrm{Dx}) 1+(\mathrm{D}) 2 /(\mathrm{Dx}) 2+\alpha(\mathrm{D}) 1(\mathrm{D}) 2 /(\mathrm{Dx}) 1(\mathrm{Dx}) 2$, where (Dx)1 and (Dx) 2 are the doses for $\mathrm{x} \%$ inhibition by drug 1 and drug 2, respectively. (D)1 and (D)2 are representative of the combinatory doses that inhibit cell growth by $\mathrm{x} \%$. A CI value of one indicates additive effects of the two drugs and a
CI value $>1$ indicates an antagonistic effect, while a $C I$ value $<1$ suggests a synergistic effect. Isobologram analysis in Fig. 2 shows a graphic representation of the CI value, where CI value $<1$ is inside the triangle, CI value $>1$ is outside the triangle, a CI value of one is on the hypotenuse. Three experimental repeats were performed to calculate $\mathrm{CI}$ values.

DAPI staining assay. Live pancreatic cancer cells were plated in 6-well plates for $24 \mathrm{~h}$, followed by treatment with the indicated drugs. After treatment for $48 \mathrm{~h}$, the cells were fixed with $4 \%$ paraformaldehyde for $20 \mathrm{~min}$, followed by DAPI staining for $10 \mathrm{~min}$ in the dark. Finally, cells were detected using immunofluorescence microscopy (DSY5000X, OPPNO).

EdU (5-ethynyl-2'-deoxyuridine) assay. Cell Light ${ }^{\mathrm{TM}}$ EdU Kit was purchased from RiboBio Co., Ltd. and the experiment was conducted according to the manufacturer's instructions. Briefly, prepared $50 \mu \mathrm{M}$ EdU DMEM medium solutions were added to treated PC cells in 96-well plates and incubated for $2 \mathrm{~h}$, followed by washing with PBS twice. Then $4 \%$ paraformaldehyde was used to fix the cells for $30 \mathrm{~min}$ and $2 \mathrm{mg} / \mathrm{ml}$ glycine was used to neutralize the remaining paraformaldehyde. Apollo staining reaction solution was used to incubate PC cells in the dark for $30 \mathrm{~min}$, followed by washing with $0.5 \%$ Triton X-100 PBS three times. Finally, Hoechst-33342 was added for $30 \mathrm{~min}$ and images were taken via immunofluorescence microscopy (DSY5000X, OPPNO).

Wound healing assay. PANC-1 cells were seeded in six-well plates, followed by incubation for $24 \mathrm{~h}$. Each well was initiated by scratching with a sterile pipette tip, followed by washing with PBS three times, and then treated with the indicated drugs in serum-free medium for $24 \mathrm{~h}$. Images at 0 and $24 \mathrm{~h}$ were taken using an inverted fluorescence microscope (DSY5000X) at $\mathrm{x} 40$ magnification. The blank area between two cell edges was calculated via ImageJ software. Wound healing percentage was calculated using the formula: [Blank area $(0 \mathrm{~h})$-blank area $(24 \mathrm{~h})] /$ Blank area $(0 \mathrm{~h}) \times 100 \%$.

Matrigel invasion assay. Cells were cultured in the culture medium in the presence of drugs at the indicated concentrations for $48 \mathrm{~h}$. DMSO with the same volume was used as the control. Cells were then trypsinized and resuspended into DMEM medium. The aforementioned cells $\left(5 \times 10^{4}\right.$ cells per well with serum-free medium) were plated in upper chamber coated with Matrigel (Corning). DMEM culture medium containing $10 \%$ FBS was used as a chemoattractant in the lower chamber. After incubation for an additional $24 \mathrm{~h}$, the invaded cells in the lower chamber were stained with $0.1 \%$ crystal violet. Finally, cell images were obtained via light microscope with charge-coupled device camera.

Transmission electron microscope. Cells were digested by $0.25 \%$ trypsin, followed by centrifugation at $400 \mathrm{x} \mathrm{g}$ for $5 \mathrm{~min}$ at $4{ }^{\circ} \mathrm{C}$ and fixation in $2.5 \%$ glutaraldehyde overnight at $4^{\circ} \mathrm{C}$. Next, the samples were fixed in $1 \%$ osmium acid, followed by dehydration and embedding with fresh epon resin, then incubated at $70^{\circ} \mathrm{C}$ vacuum oven for 2 days. Appropriate areas of the samples were selected and ultrathin sections of $0.08 \mu \mathrm{m}$ were stained with lead citrate and uranyl acetate for 5-10 min at about 
$95^{\circ} \mathrm{C}$ empirically. Finally, these sections were determined by a transmission electron microscope (TEM; JEM1230, Tokyo).

Western blotting. Cultured cells were treated with the indicated drugs for $48 \mathrm{~h}$, followed by lysing in RIPA buffer and denaturation. Protein concentration was determined by bicinchoninic acid assay system (Beyotime). Protein sample (50 $\mu \mathrm{g}$ per lane) was separated by $12 \%$ SDS-PAGE gel, followed by electrophoretical transfer to nitrocellulose membranes. The membranes were then blocked with $5 \%$ non-fat milk for $30 \mathrm{~min}$ at room temperature. Primary antibodies including anti-caspase-3 (ABclonal, A2156), anti-cleaved-caspase-3 (ABclonal, A11021), anti-PARP (ABclonal, A19596), anti-cleaved-PARP (ABclonal, A19612), anti-p-MLKL (Abcam, ab196436), anti-MLKL (Abcam, ab184718), anti-N-cadherin (Abcam, ab76011), anti-E-cadherin (Abcam, ab40772), anti-Vimentin (Abcam, ab92547), anti-MMP2 (CST, 4022), anti-MMP9 (CST, 3852S), anti-TIMP1 (CST, 8946S) and anti-TIMP2 (CST, 5738S) antibodies were diluted in primary antibody dilution buffer (Coolaber, SL1360) and incubated with nitrocellulose membranes at $4^{\circ} \mathrm{C}$ overnight. Next, the membranes were incubated with the corresponding secondary antibodies conjugated with horseradish peroxidase at room temperature for $2 \mathrm{~h}$, followed by detection via an enhanced chemiluminescence detection kit (Thermo Fisher Scientific). GAPDH (CST, 5174S) was used as the control. Images were captured via a chemiluminescence imaging system (ChemiScope 6000 Exp).

Statistical analysis. Data were analyzed using SPSS20.0 and presented as mean \pm standard deviation. ANOVA followed by the Bonferroni-multiple comparison test was used for statistical analysis to compare values among multiple groups. When the overall difference across the multiple groups was significant, Bonferroni-adjusted significance tests were used for pairwise comparisons. $\mathrm{P}<0.05$ indicated statistical significance.

\section{Results}

Curcumin induced morphologic changes of PC cells and inhibited cell viability. We detected the morphologic changes of PANC-1, MIAPaCa-2 and HPAF-II pancreatic cancer cells in the presence of curcumin by inverted microscope. Cells treated with $50 \mu \mathrm{M}$ curcumin exhibited a different profile with a shrinkage of cell size, while cells in the controlled group exhibited blurry features and attached tightly to the well of the plate (Fig. 1A-C). The morphological changes are more obvious with the concentrations of curcumin increasing, the data of $0-20 \mu \mathrm{M}$ are not shown. Next, we used MTT assay to detect cell viability. As expected, cell viability was significantly reduced in PC cells treated with curcumin. Notably, the suppressive effects of curcumin on cell viability of PC cells occurred in a dose-dependent manner (Fig. 1D). The $\mathrm{IC}_{50}$ of curcumin in PANC-1, MIAPaca-2 and HPAF-II were 9.87, 13.49 and $45.96 \mu \mathrm{M}$, respectively, in our detection. Three experimental repeats were carried out to calculate IC values.

Curcumin showed synergistic effects with either gemcitabine or docetaxel on PC cells. To investigate whether curcumin has synergistic effects with gemcitabine or docetaxel, we
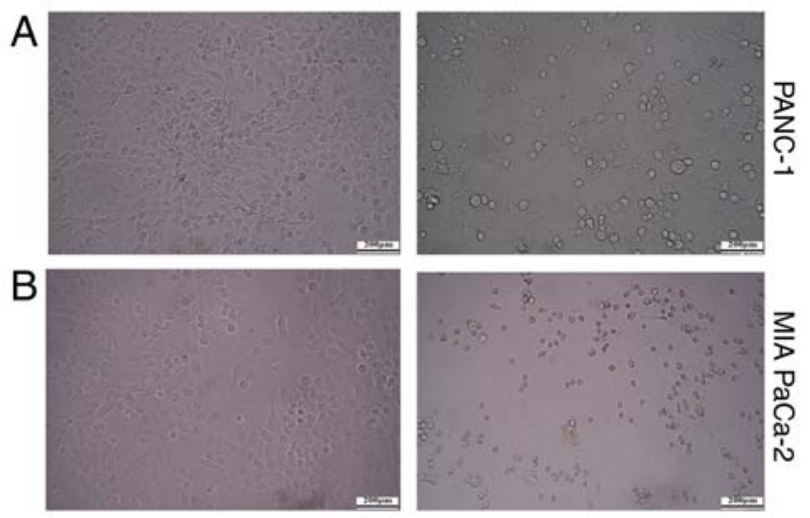

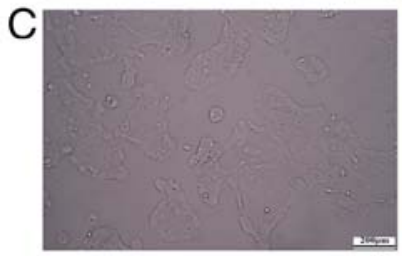

DMSO

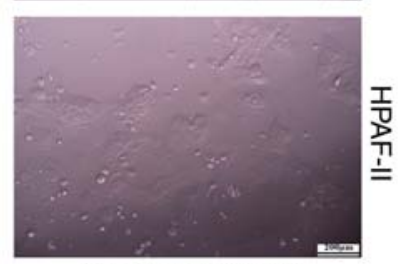

Curcumin $(50 \mu \mathrm{M})$

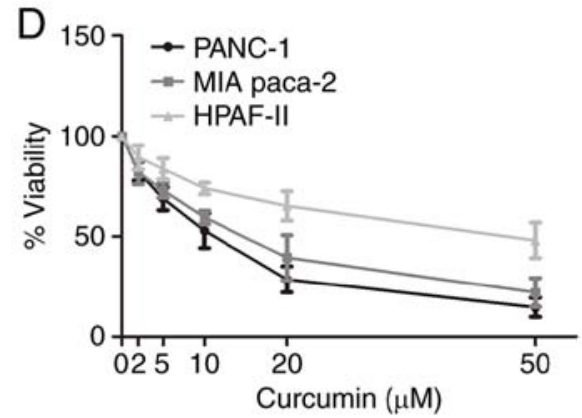

Figure 1. Curcumin induced morphologic changes of PC cells and inhibited cell viability. Morphological changes of (A) PANC-1, (B) MIA PaCa-2 and (C) HPAF-II cells after treatment with DMSO and curcumin for $48 \mathrm{~h}$ at the indicated concentrations. The changes were visualized by inverted optical microscope. (D) Viability of PANC-1, HPAF-II and MIA PaCa-2 cells were detected by MTT assay in presence of curcumin at different concentrations.

administered curcumin together with gemcitabine or docetaxel of different concentrations to PC cells. As shown in Fig. 2A, gemcitabine at $2 \mu \mathrm{M}$ alone mildly inhibited cell proliferation with a cell viability of $(83 \pm 5.027) \%$, while combination with curcumin $(5 \mu \mathrm{M})$ induced significant inhibition on proliferation of PANC-1 cells with viability of $(22.33 \pm 2.656) \%$. Similarly, curcumin $(5 \mu \mathrm{M})$ in combination with gemcitabine $(5,10 \mu \mathrm{M})$ significantly inhibited cell proliferation compared with gemcitabine $(5,10 \mu \mathrm{M})$ alone $[(15.52 \pm 3.928) \%$ vs. $(62.47 \pm 4.573) \%, \mathrm{P}<0.01 ;(15.13 \pm 2.852)$ vs. $(55.73 \pm 5.1) \%$, $\mathrm{P}<0.01]$. The $\mathrm{CI}$ values of gemcitabine plus curcumin were $0.208,0.183$ and 0.237 when they were given with the ratios of 1:2.5, 1:1 and 2:1, respectively (Fig. 2C). Similarly, docetaxel had synergistic effects with curcumin. The viability of PC cells treated with curcumin $(5 \mu \mathrm{M})$ plus docetaxel $(2,5,10 \mathrm{nM})$ was obviously decreased when compared to docetaxel alone $(2,5,10 \mathrm{nM})[(47.27 \pm 3.268) \%$ vs. $(64.57 \pm 2.735) \%, \mathrm{P}<0.05$; $(35.33 \pm 3.708)$ vs. $(54.67 \pm 2.751) \%, \mathrm{P}<0.05 ;(28.6 \pm 4.063)$ vs. $(47 \pm 1.65) \%, \mathrm{P}<0.005]$ (Fig. $2 \mathrm{~B})$. The CI values of docetaxel (nM) plus curcumin $(\mu \mathrm{M})$ were $0.576,0.432$ and 0.38 when they were given with the ratios of $1: 2.5,1: 1$ and $2: 1$, respectively (Fig. 2D). Consistently, similar results were obtained 

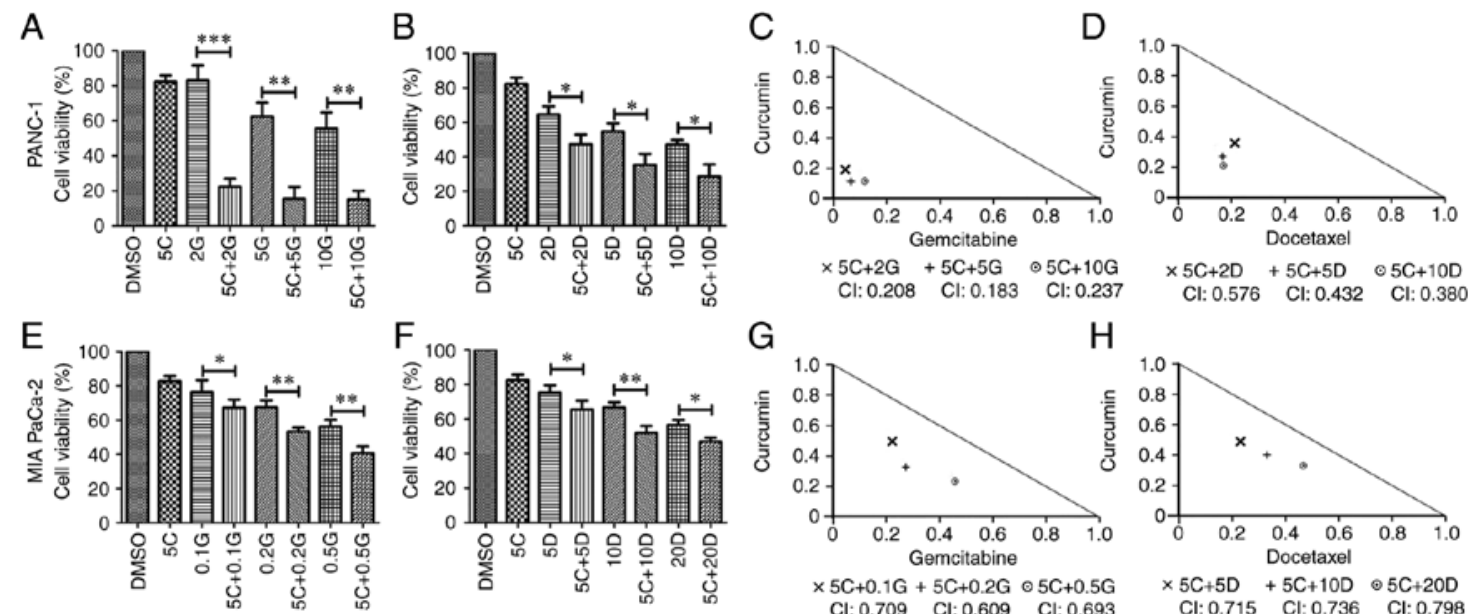

$\mathrm{G}$

$\mathrm{H}$
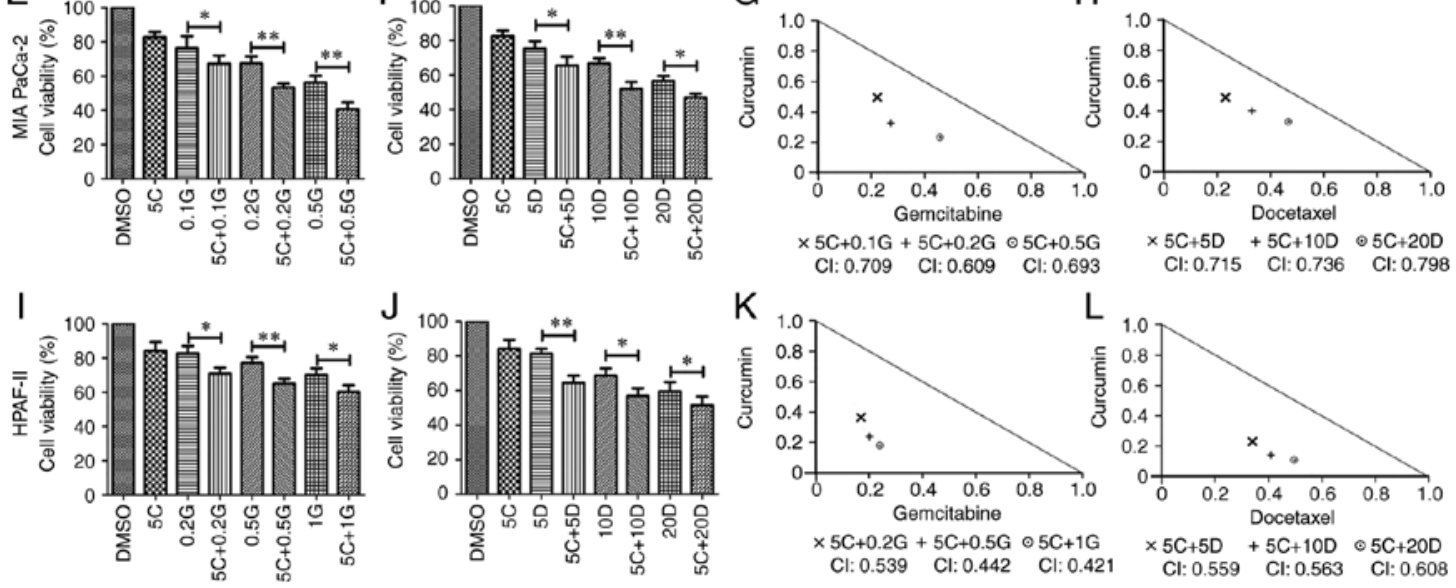

Figure 2. Effects of curcumin with gemcitabine or docetaxel on cell viability of PANC-1, MIA PaCa-2 and HPAF-II cells. (A and B) Combinatory effects of curcumin with gemcitabine or docetaxel on cell viability of PANC-1 cells were determined by MTT assay. Data were collected from three independent experiments. (C and D) Isobologram analysis was used to assess the synergistic effects of curcumin with either gemcitabine or docetaxel on PANC-1 cells. The $\mathrm{CI}$ values indicate the synergistic effects at different drug combinations. (E and F) Combinatory effects of curcumin with either gemcitabine or docetaxel on cell viability of MIA PaCa-2 cells were determined by MTT assay. ( $\mathrm{G}$ and $\mathrm{H}$ ) Isobologram analysis was used to assess the synergism of curcumin with either gemcitabine or docetaxel on MIA PaCa-2 cells. The CI values depict the synergistic effects at indicated combination drugs. (I and J) Combinatory effects of curcumin with either gemcitabine or docetaxel on cell viability of HPAF-II cells were determined by MTT assay. (K and L) Isobologram analysis was conducted to evaluate the synergism of curcumin with gemcitabine or docetaxel on HPAF-II cells. The CI values depict the synergistic effects at different drug combinations. All the experiments were conducted in triplicate. CI, Combination index. 5C: $5 \mu \mathrm{M}$ curcumin, $2 \mathrm{G}: 2 \mu \mathrm{M}$ gemcitabine, $5 \mathrm{G}: 5 \mu \mathrm{M}$ gemcitabine, 10G: $10 \mu \mathrm{M}$ gemcitabine, $5 \mathrm{C}+2 \mathrm{G}: 5 \mu \mathrm{M}$ curcumin plus $2 \mu \mathrm{M}$ gemcitabine, $5 \mathrm{C}+5 \mathrm{G}: 5 \mu \mathrm{M}$ curcumin in combination with $5 \mu \mathrm{M}$ gemcitabine, $5 \mathrm{C}+10 \mathrm{G}: 5 \mu \mathrm{M}$ curcumin in combination with $10 \mu \mathrm{M}$ gemcitabine, 2D: $2 \mathrm{nM}$ docetaxel, 5D: $5 \mathrm{nM}$ docetaxel, 10D: $10 \mathrm{nM}$ docetaxel, 5C+2D: $5 \mu \mathrm{M}$ curcumin in combination with $2 \mathrm{nM}$ docetaxel, 5C+5D: $5 \mu \mathrm{M}$ curcumin in combination with $5 \mathrm{nM}$ docetaxel, 5C+10D: $5 \mu \mathrm{M}$ curcumin in combination with $10 \mathrm{nM}$ docetaxel. ${ }^{*} \mathrm{P}<0.05$, ${ }^{* *} \mathrm{P}<0.01$ and ${ }^{* * *} \mathrm{P}<0.001$.
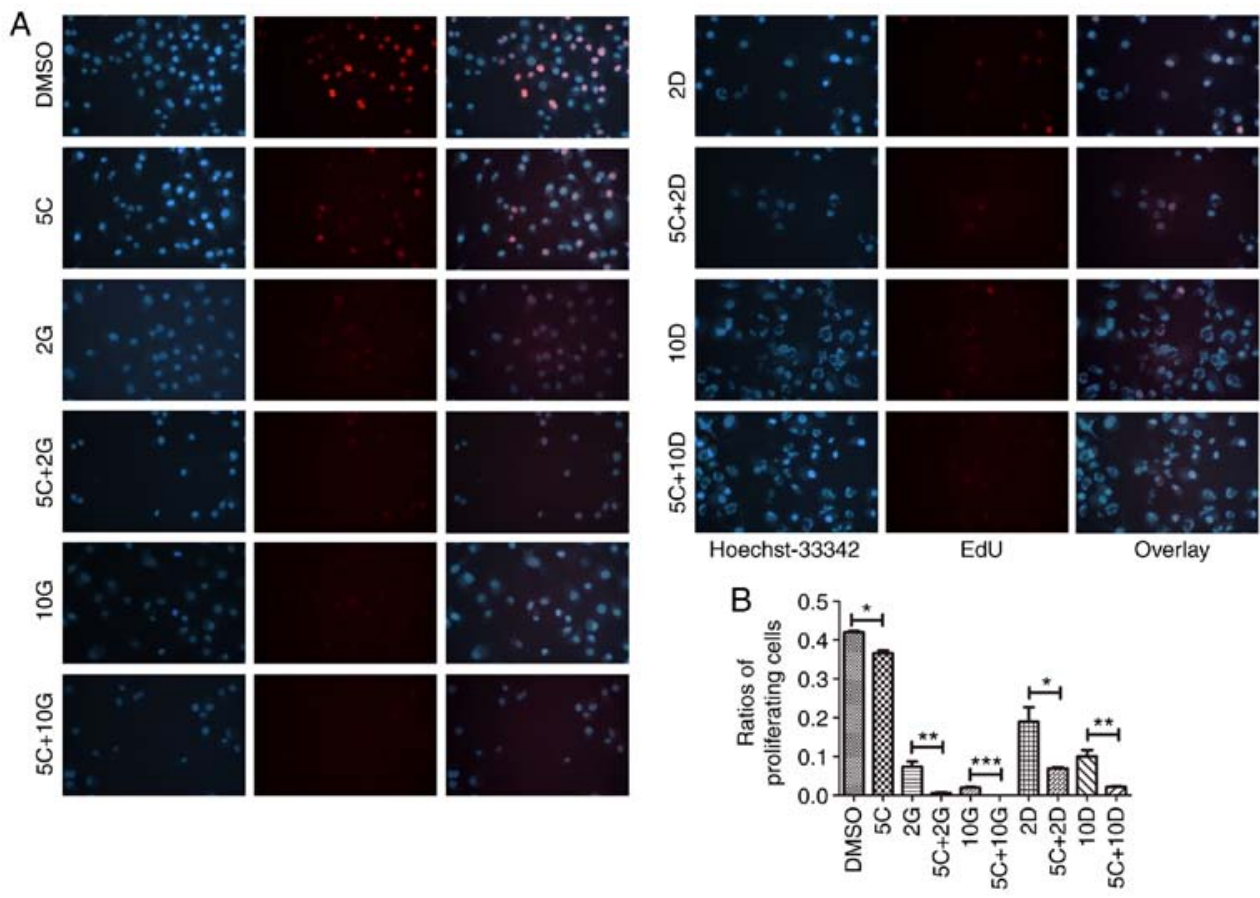

Figure 3. Curcumin inhibited proliferation of PANC-1 cells and enhanced the anti-proliferation effects of gemcitabine or docetaxel. (A) Proliferation of PANC-1 cells was determined by EdU assay. Nuclei of proliferating cells were stained for red which were pink in the overlaid image. (B) Percentage of nuclei in pink was performed to evaluate the relative proliferation ability of PANC-1 cells $\left({ }^{*} \mathrm{P}<0.05,{ }^{* * *} \mathrm{P}<0.01\right.$ and $\left.{ }^{* * * *} \mathrm{P}<0.001\right)$. 


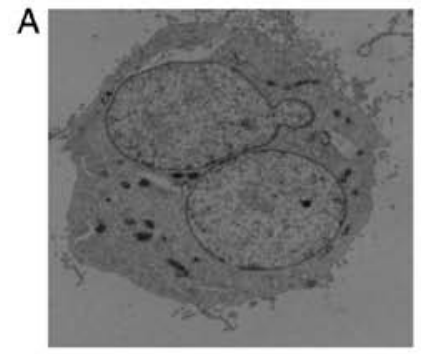

DMSO

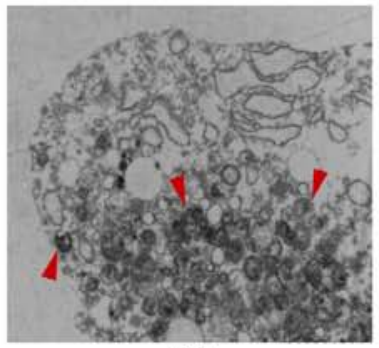

$10 \mathrm{D}$

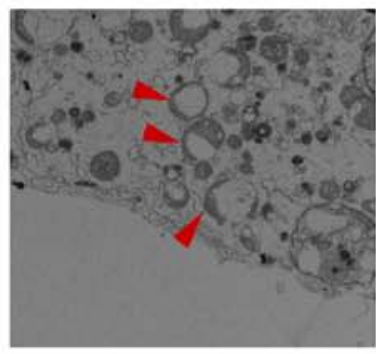

$20 \mathrm{C}$

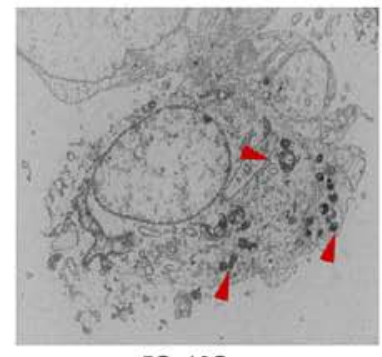

$5 C+10 G$

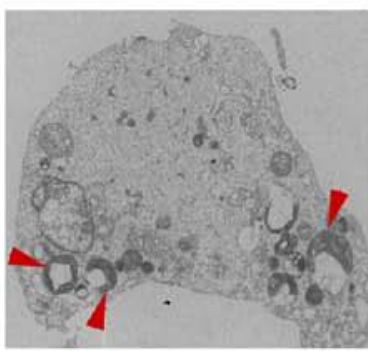

$10 \mathrm{G}$

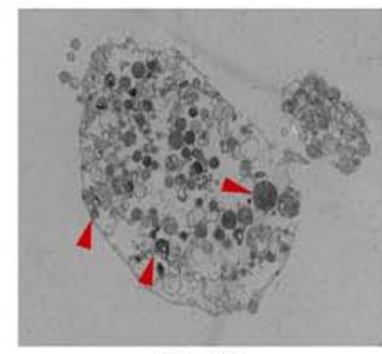

$5 C+10 D$
B

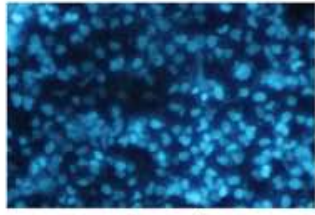

Control

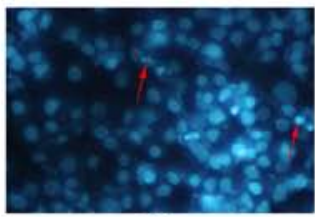

$2 \mathrm{G}$

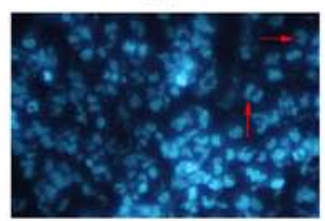

$2 \mathrm{D}$

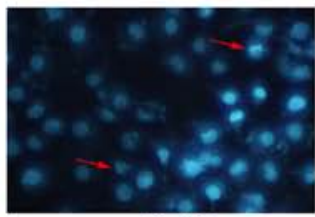

$5 \mathrm{C}+2 \mathrm{G}$

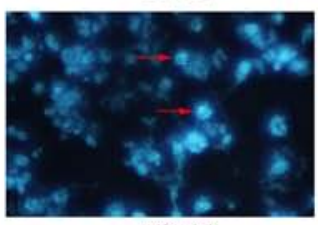

$5 C+2 D$

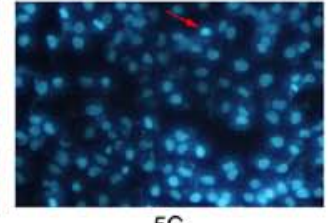

$5 \mathrm{C}$

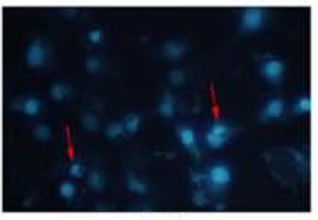

$10 G$

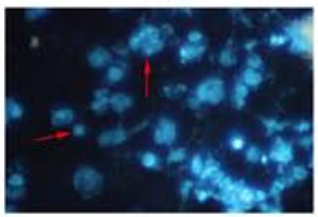

$10 \mathrm{D}$

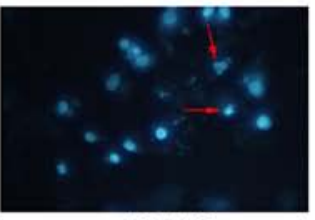

$5 C+10 G$

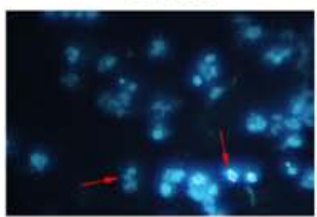

$5 C+10 D$

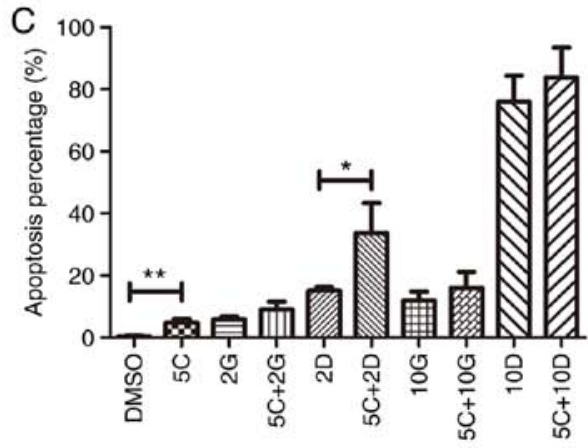

Figure 4. Curcumin induced apoptosis of PANC-1 cells and enhanced the pro-apoptotic effects of gemcitabine or docetaxel on PANC-1 cells. (A) TEM was conducted to observe morphological changes of apoptosis and necrosis in the indicated groups. (B) Apoptotic morphological changes including nuclear fragmentation and condensation were observed in DAPI staining experiments. Red arrows: Typical nuclear changes of apoptotic cells. (C) Statistical analysis of apoptosis percentage on PANC-1 cells under different drug combinations ( ${ }^{*} \mathrm{P}<0.05$ and $\left.{ }^{* *} \mathrm{P}<0.01\right) .10 \mathrm{C}: 10 \mu \mathrm{M}$ curcumin, $20 \mathrm{C}$ : $20 \mu \mathrm{M}$ curcumin.

from MIAPaCa-2 and HPAF-II cells (Fig. 2E-L). These aforementioned results showed that curcumin has a synergistic effect with either gemcitabine or docetaxel on suppressing cell viability of $\mathrm{PC}$.
Curcumin enhanced the anti-proliferation effects of either gemcitabine or docetaxel on PC cells. Next, we determined whether curcumin could have synergistic effects with gemcitabine or docetaxel on the proliferation of PC cells. 

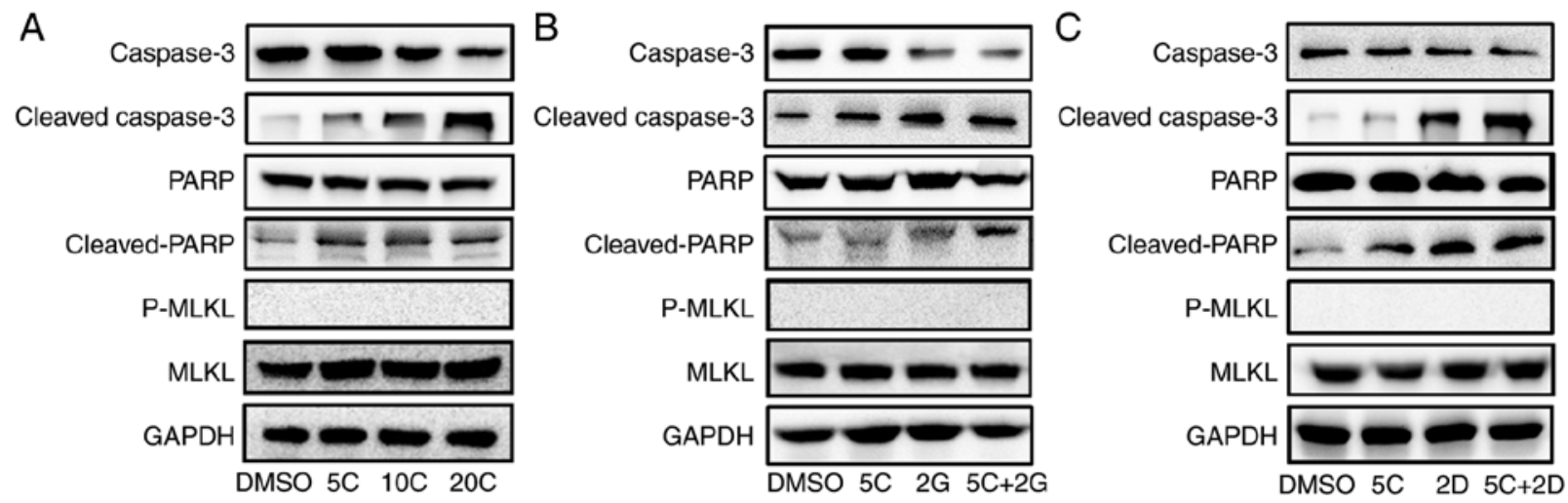

Figure 5. Curcumin inhibited the apoptosis-related caspase-3/PARP signaling pathway in PANC-1 cells. (A-C) The expression level of caspase-3, cleaved-caspase-3, PARP, cleaved-PARP, p-MLKL and MLKL in PANC-1 cells under different drug combinations were detected by western blot analysis. $G A P D H$ was used as the internal reference.

Relative proliferation ability was assessed by the ratios of proliferating cells using EdU assay. The proliferating cell treatment with curcumin $(5 \mu \mathrm{M})$ was significantly lower than that in the control group $(\mathrm{P}<0.05)$ (Fig. 3A and $\mathrm{B})$. The proliferation of $\mathrm{PC}$ cells treated with curcumin $(5 \mu \mathrm{M})$ plus gemcitabine $(2 \mu \mathrm{M})$ were significantly decreased compared to gemcitabine alone $(2 \mu \mathrm{M})[(0.558 \pm 0.279)$ vs. $(7.228 \pm 1.412) \%$, $\mathrm{P}<0.01]$. Interestingly, proliferation of $\mathrm{PC}$ cells in curcumin $(5 \mu \mathrm{M})$ plus gemcitabine $(10 \mu \mathrm{M})$ group was completely inhibited (Fig. 3A and B). Similarly, cell proliferation after treatment with curcumin $(5 \mu \mathrm{M})$ plus docetaxel $(2$ or $10 \mathrm{nM})$ groups were significantly lower than docetaxel $(2$ or $10 \mathrm{nM})$ alone $[(6.961 \pm 0.286)$ vs. $(19.26 \pm 3.499) \%, \mathrm{P}<0.05 ;(2.201 \pm 0.11)$ vs. $(10.3 \pm 1.396) \%, \mathrm{P}<0.01]$ (Fig. $3 \mathrm{~A}$ and B). Our results indicated that curcumin is a potential adjuvant to enhance the anti-proliferation effects of either gemcitabine or docetaxel for PC cells.

Curcumin induced apoptosis of PC cells and enhanced the pro-apoptotic effects of either gemcitabine or docetaxel on $P C$ cells. To assess whether curcumin mediated suppression of PC cell growth was correlated with cell apoptosis, we used TEM, DAPI staining assay as well as western blot analysis after treatment with 5, 10,20 $\mu \mathrm{M}$ curcumin, 2, $10 \mu \mathrm{M}$ gemcitabine, 2, $10 \mu \mathrm{M}$ docetaxel, $5 \mu \mathrm{M}$ curcumin plus $2,10 \mu \mathrm{M}$ gemcitabine or docetaxel for $48 \mathrm{~h}$. As expected, treatment with different drugs at the indicated concentrations triggered increased morphological changes of apoptosis and necrosis in PC cells by TEM (Fig. 4A). Curcumin at $5 \mu \mathrm{M}$ induced significantly increased cell apoptosis in PC cells compared with the control [(4.633 \pm 1.11$)$ vs. $(0.327 \pm 0.119) \%, \mathrm{P}<0.001$; Fig. $4 \mathrm{~B}$ and $\mathrm{C}]$. These data demonstrated that curcumin could induce cell apoptosis and necrosis of PC cells in vitro.

To further investigate the molecular mechanism of apoptosis and necrosis induced by curcumin, western blotting was used to determine the protein levels of classical apoptosis-related molecules including caspase-3, cleaved-caspase-3, PARP and cleaved-PARP, which were considered as classical apoptosis-related molecules. The results showed that the expression level of caspase- 3 was downregulated, accompanied by concomitantly increased expression level of cleaved-caspase-3 after treatment with curcumin alone. Western blotting showed protein level of cleaved-PARP was significantly increased after curcumin treatment, while there was no significant change in PARP (Fig. 5A). These results indicated that the apoptosis-related caspase-3/PARP signaling pathway may play a critical role in curcumin-induced apoptosis of PC cells. p-MLKL, which was regarded as a hallmark of necroptosis, was also detected by western blot analysis in the present study. However, no significant change in p-MLKL was observed (Fig. 5A).

Then, we investigated whether curcumin enhanced the pro-apoptotic effects of gemcitabine or docetaxel on PC cells by DAPI staining. Notably, treatment with curcumin $(5 \mu \mathrm{M})$ together with docetaxel $(2 \mathrm{nM})$ induced significantly increased apoptosis of PC cells in comparison with docetaxel $(2 \mathrm{nM})$ alone [(33.73 \pm 4.787$)$ vs. $(15.63 \pm 1.589) \%$; $\mathrm{P}<0.05]$. Similar trends were observed in other groups but no statistical significance (Fig. 4B and C). Additionally, we observed significant apoptotic features of cells in each group treated with drugs by TEM (Fig. 5A). Furthermore, caspase-3/PARP signaling pathway was obviously activated in the presence of gemcitabine plus curcumin or docetaxel plus curcumin (Fig. 5B and C). These results suggested that curcumin has a potent ability to enhance the pro-apoptotic effects of chemotherapy drugs on PC cells in vitro and exerts different influences on pro-apoptosis effect of different drugs.

Curcumin inhibited PC cell migration and benefitted the suppressive ability of gemcitabine or docetaxel on cell migration. To further detect the effects of curcumin on cell migration, we used wound healing assay to determine the migration ability of PC cells under different drug treatment. As expected, curcumin at $5 \mu \mathrm{M}$ resulted in obvious reduction in recovery ratio of $\mathrm{PC}$ cells in comparison with control [(35.7 \pm 2.155$)$ vs. $(46.43 \pm 1.105) \%$; $\mathrm{P}<0.05]$ (Fig. 6A and B).

Next, we determined whether curcumin reinforced suppressive ability of gemcitabine or docetaxel on cell migration by using scratching assay. Treatment of curcumin $(5 \mu \mathrm{M})$ together with gemcitabine $(2 \mu \mathrm{M})$ exhibited stronger ability to inhibit cell migration in comparison with gemicitabine alone $(2 \mu \mathrm{M})$ $[(11.67 \pm 3.159)$ vs. $(28.17 \pm 2.906) \% ; \mathrm{P}<0.05]$ (Fig. $6 \mathrm{~A}$ and B). Similarly, a combination of curcumin $(5 \mu \mathrm{M})$ and gemcitabine $(10 \mu \mathrm{M})$ showed significantly suppressive effect on PC cells in 


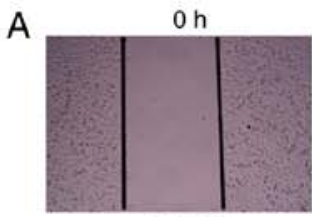

DMSO

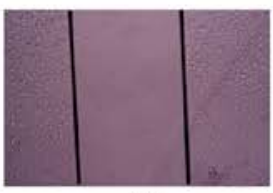

$2 \mathrm{G}$

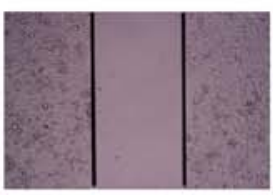

$10 \mathrm{G}$

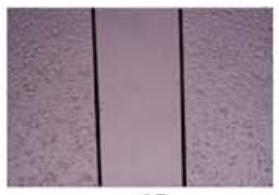

2D

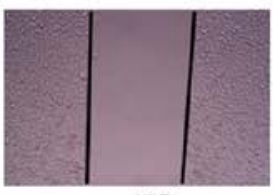

$10 \mathrm{D}$

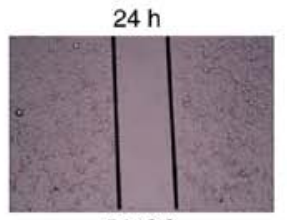

DMSO

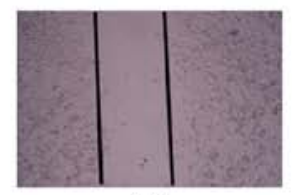

$2 \mathrm{G}$

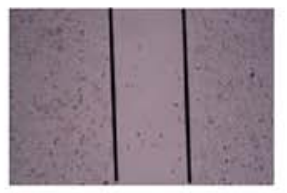

$10 \mathrm{G}$

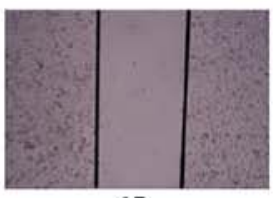

2D

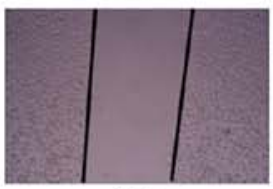

$10 \mathrm{D}$

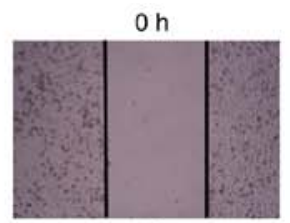

$5 C$

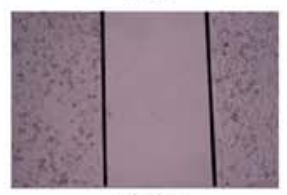

$5 \mathrm{C}+2 \mathrm{G}$

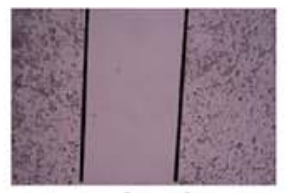

$5 \mathrm{C}+10 \mathrm{G}$

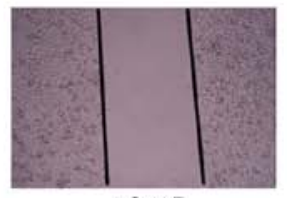

$5 \mathrm{C}+2 \mathrm{D}$

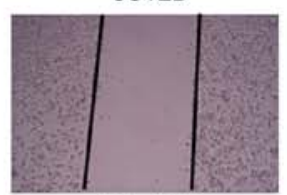

$5 \mathrm{C}+10 \mathrm{D}$
$24 \mathrm{~h}$

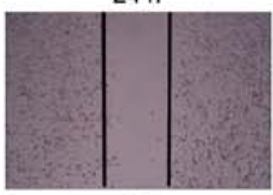

$5 \mathrm{C}$

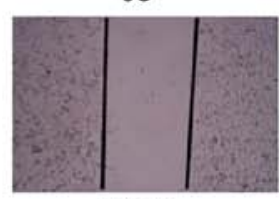

$5 \mathrm{C}+2 \mathrm{G}$

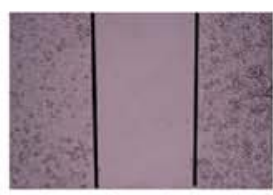

$5 C+10 G$

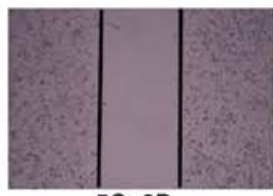

$5 \mathrm{C}+2 \mathrm{D}$

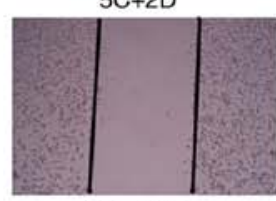

$5 C+10 D$
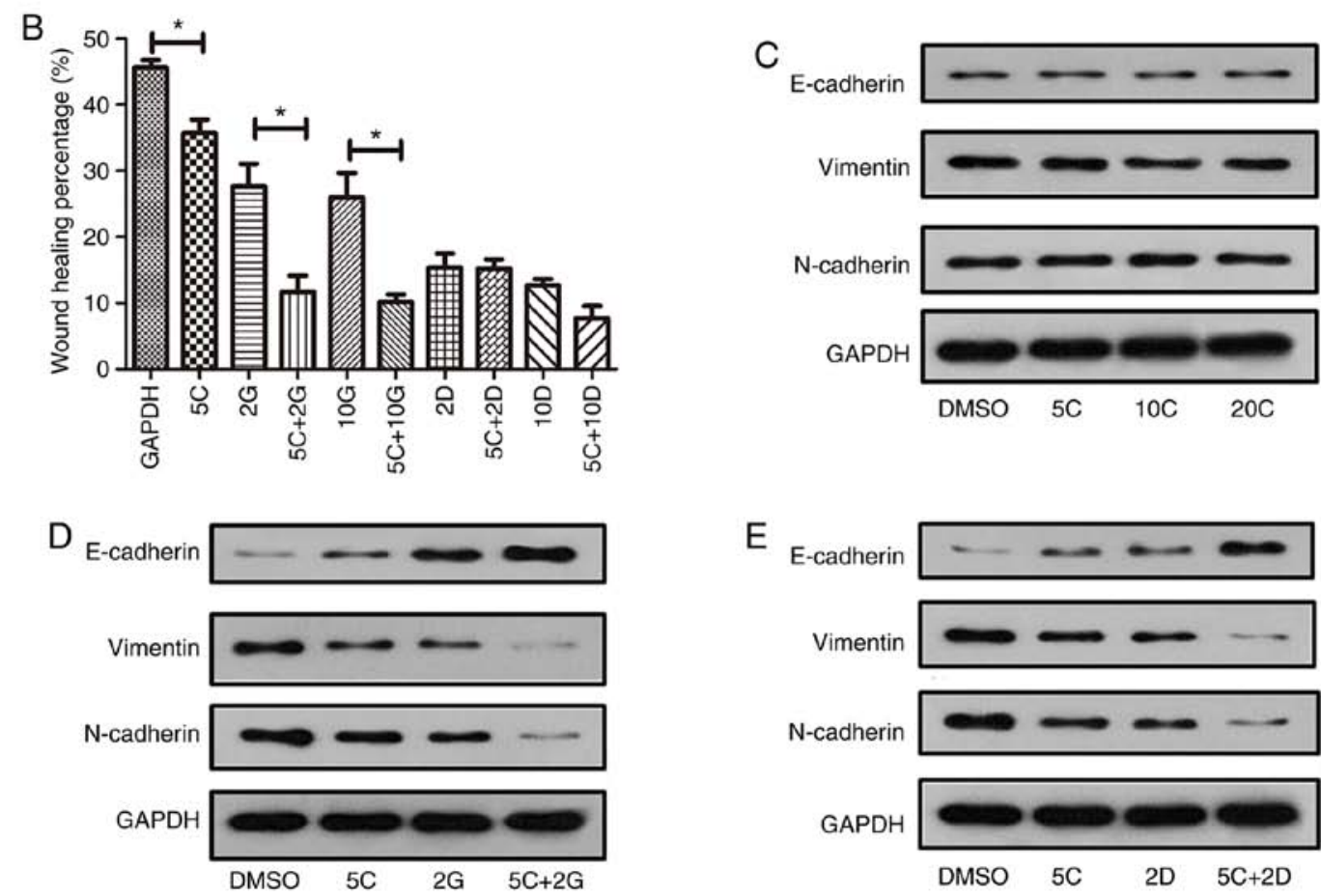

Figure 6. Curcumin inhibited migration of PANC-1 cells and enhanced anti-migration ability of gemcitabine or docetaxel. (A) Images of wounded areas were determined by inverted microscope at 0 and $24 \mathrm{~h}$. (B) Statistical analysis for wound healing percentage on PANC-1 cells under different drug combinations. ${ }^{*} \mathrm{P}<0.05$ indicated statistically significant difference. (C-E) Expression of N-cadherin, E-cadherin and Vimentin in indicated combination groups were determined by western blot analysis.

comparison with gemcitabine alone $(10 \mu \mathrm{M})[(10.83 \pm 2.677)$ vs. $(25.97 \pm 3.302) \%$; $\mathrm{P}<0.05]$ (Fig. 6A-C). Moreover, expression of $\mathrm{N}$-cadherin and Vimentin were obviously reduced in the gemcitabine $(2 \mu \mathrm{M})$ plus curcumin $(5 \mu \mathrm{M})$ group (Fig. $6 \mathrm{D})$, while the expression of E-cadherin was obviously increased in the gemcitabine $(2 \mu \mathrm{M})$ plus curcumin $(5 \mu \mathrm{M})$ group (Fig. $6 \mathrm{D})$. 


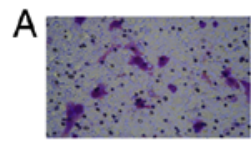

DMSO

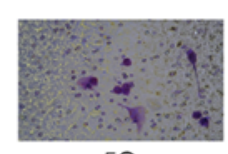

$5 \mathrm{C}$
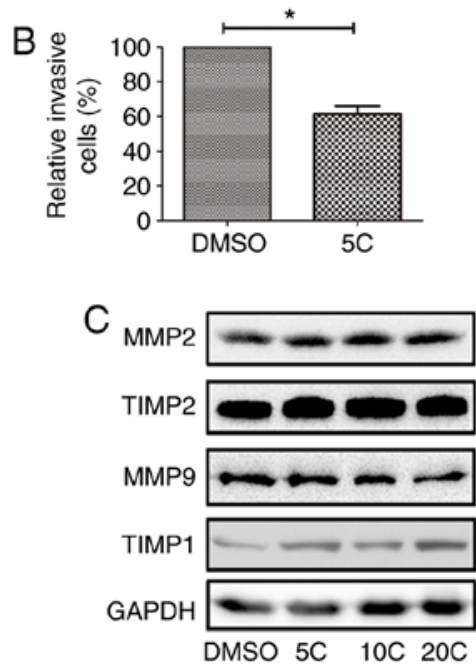

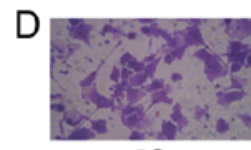

$2 \mathrm{G}$
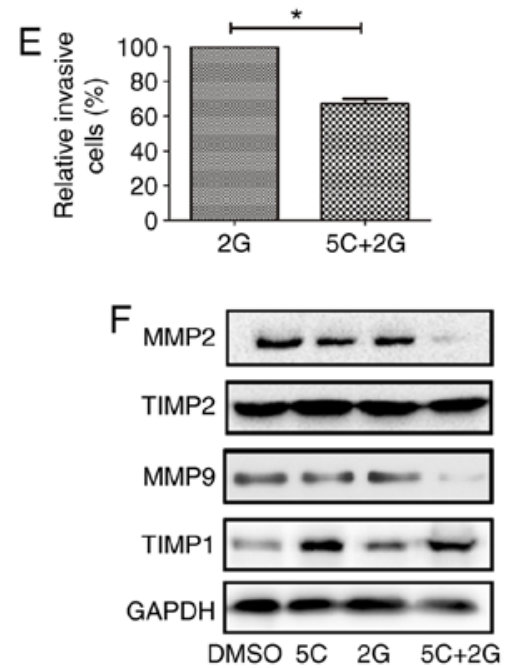

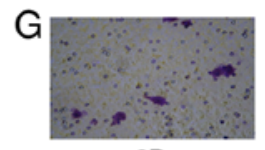

$2 \mathrm{D}$
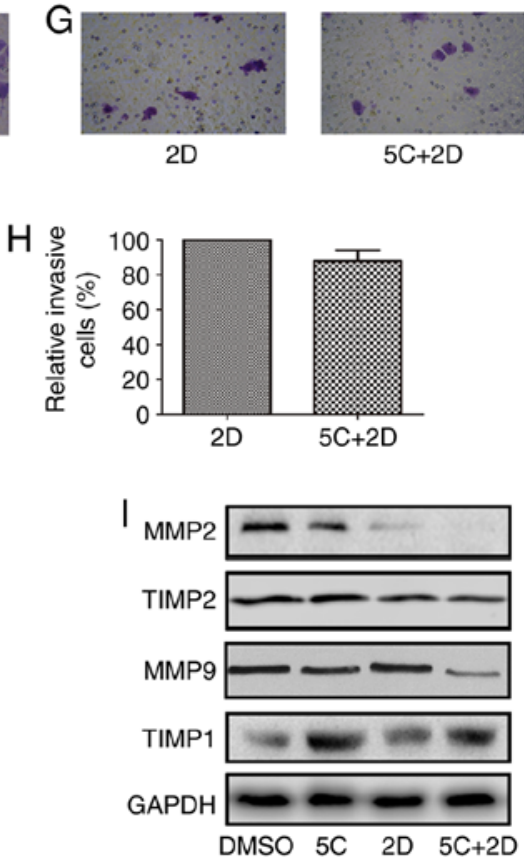

Figure 7. Curcumin inhibited invasion of PANC-1 cells alone or combined with gemcitabine or docetaxel. (A-C) Matrigel invasion assay was conducted to observe the invasion capacity of PANC-1 cells under different drug regimens. (D-F) Quantitative analysis of invasive PANC-1 cells when added with or without curcumin $($ P $<0.05)$. (G-I) Expression of MMP2, MMP9, TIMP1 and TIMP2 in PANC-1 cells at indicated treatment were measured by western blot analysis.

Although curcumin showed no significant enhancement to inhibitory effect of docetaxel, expression of $\mathrm{N}$-cadherin and Vimentin were slightly reduced in the docetaxel $(2 \mathrm{nM})$ plus curcumin (5 $\mu \mathrm{M})$ group, while E-cadherin showed slight increase (Fig. 6E). These results suggest that curcumin reinforced the ability of gemcitabine to suppress migration of PC cells.

Combination application of curcumin with gemcitabine or docetaxel inhibited invasion of PC cells. To gain a better understanding of the anti-invasion ability of curcumin in combination with gemcitabine or docetaxel, we conducted Matrigel invasion assay to assess the invasion ability of PC cells under different drug combination. As expected, curcumin at $5 \mu \mathrm{M}$ induced an average of $38.67 \%$ reduction of invaded PC cells compared with control (Fig. 7A and B). Interestingly, TIMP1, a member of natural inhibitor for the matrix metalloproteinases (MMPs), was upregulated in a dose-dependent manner when treated with curcumin alone (Fig. 7C). Similarly, an average of $32.77 \%$ reduction of invaded PC cells was found in curcumin $(5 \mu \mathrm{M})$ plus gemcitabine $(2 \mu \mathrm{M})$ group compared with gemcitabine $(2 \mu \mathrm{M})$ alone (Fig. 6D and E). In addition, MMP2 and MMP9 expression was significantly reduced after treatment with gemcitabine $(2 \mu \mathrm{M})$ plus curcumin $(5 \mu \mathrm{M})$ group while the expression of TIMP1 was upregulated in curcumin $(5 \mu \mathrm{M})$ group and gemcitabine $(2 \mu \mathrm{M})$ plus curcumin $(5 \mu \mathrm{M})$ group (Fig. 7F). Treatment with curcumin $(5 \mu \mathrm{M})$ plus docetaxel $(2 \mathrm{nM})$ showed little inhibition for invasion of PANC-1 cells compared with docetaxel alone ( $2 \mathrm{nM})$, without statistical significance (Fig. 7G and H). Expression of MMP2 and MMP9 was obviously reduced in docetaxel (2 nM) plus curcumin $(5 \mu \mathrm{M})$ group, accompanied by the upregulation of TIMP1 (Fig. 7I). These results indicated that curcumin would be a promising adjuvant to inhibit invasion of PC cells.

\section{Discussion}

Increasing evidence has indicated that curcumin exerts anti-tumor effects on the proliferation, apoptosis, migration as well as invasion of PC cells (22-25). Multiple signaling pathways may be involved in this circumstance, including modulation of inhibitor of apoptosis proteins (IAP) and downregulation of YAP/TAZ expression $(26,27)$. Other studies have shown that downregulation of NEDD4 with concomitant upregulation of PTEN and p53 may be involved in this procedure (28). Youns and Fathy have demonstrated that activation of TNFR, CASP8, $C A S P 3, B I D, B A X$, and downregulation of $N F-\kappa B, N D R G 1$ and $B C L 2 L 10$ genes may be involved in curcumin-mediated effects on PC cells (29). Our results were in accordance with these findings. Curcumin was reported to produce fluorescence emission (excitation spectra from 300 to $540 \mathrm{~nm})(26,30,31)$. Consequently, we did not use flow cytometry to detect apoptosis but selected TEM to detect apoptosis. In the present study, we have found that caspase-3/PARP signaling pathway is involved in curcumin-induced apoptosis of PC cells.

To the best of our knowledge, the current study has several novelties. Firstly, the present study is the first to determine the combinatory effects of curcumin plus docetaxel or gemcitabine by using the CalcuSyn software. Secondly, we employed three pancreatic cells lines with different genetic backgrounds to test the combinatory effects of the drugs, providing convincing data for the combinatory drug use. PANC-1 and MIA paca-2 have different chromosomal aberrations, while HPAF-II is a kind of cell line derived from pancreatic adenocarcinoma patients with metastases. Notably, the combinatory treatment of gemcitabine or docetaxel with curcumin could significantly strengthen this process. Thirdly, necroptosis has been demonstrated to be involved in some drug-induced tumor cell death 
and the p-MLKL is a marker of necroptosis (32-35). Whether necroptosis participates in the cell death caused by curcumin, gemcitabine or docetaxel is unknown; however, we detected the marker p-MLKL to check the necroptosis pathway, which is novel, compared to other similar studies. However, we did not find significant change in the expression of MLKL/p-MLKL, suggesting that necroptosis is not involved in curcumin-induced death of PC cells.

Targeting metastasis is crucial to the treatment of PC. Wang et al have reported that curcumin has the capacity to inhibit mesenchymal transition (EMT) by targeting cancer-associated fibroblasts (CAFs), which plays a pivotal role in the metastasis of PC (36). In the cancer process, it is considered that epithelial-derived cancer cells are reversible, trans-differentiated and with low affinity in cell-cell adhesion, and then disseminated through blood or lymphatics to other sites via invasion $(37,38)$. E-cadherin, N-cadherin, Vimentin, MMP2, MMP9, TIMP1, TIMP2 are common molecules involved in metastasis $(38,39)$. In addition to cell migration during metastasis, EMT also influences resistance to anoikis and apoptosis, blocks senescence, enhances survival, facilitates genomic instability, causes cancer stem cell (CSC) activity, alters metabolism, and induces drug resistance and immune suppression. Notably, both cadherin and Vimentin seem to be involved in this procedure. Our results showed that combinatory treatment significantly downregulated MMP2/MMP9/N-cadherin/Vimentin and upregulated TIMP1/TIMP2/E-cadherin. Therefore, curcumin is a potential candidate to strengthen the current chemotherapeutic regimens for metastatic PC. Yoshida et al have reported that curcumin can sensitize chemo-resistant cancer cells via downregulating the expression of EZH2 and lncRNA PVT1, suggesting that curcumin may have the synergistic effects with gemcitabine on PC cells (40). In our experiments, curcumin exhibited strong synergistic effects with either gemcitabine or docetaxel on three PC cell lines by using Calcusyn software. The CI values of gemcitabine plus curcumin with the ratios of 1:2.5, 1:1 and 2:1 were all $<0.5$, indicating the strong synergistic effects of the two drugs. Similarly, docetaxel also exhibited a synergistic effect with curcumin on PC cells. These data suggest that addition of low dosage of curcumin into the chemotherapeutic regimens containing gemcitabine or docetaxel for the treatment of PC patients may be a promising strategy.

In conclusion, results of the present study have demonstrated that curcumin has synergistic effects with either gemcitabine or docetaxel on PC cells. Combination of chemotherapeutic drugs with curcumin may be an alternative choice for the treatment of clinical PC patients.

\section{Acknowledgements}

We would like to thank Professor Qui-ping Zhang of Wuhan University School of Basic Medical Sciences for experiment technical guidance. We would like to thank Yu-fang Zhu and Ming Xu for assistance with cell culture.

\section{Funding}

This study was supported by the Fundamental Research Funds for the Central Universities in Wuhan University (China) (grant no. 2042019kf0131).

\section{Availability of data and materials}

The datasets used and/or analyzed in the current study are available from the corresponding author on reasonable request.

\section{Authors' contributions}

LS and XYL designed the study. XYL performed the statistical analysis. PL, QY, HL, SQY and LPB acquired the data and performed the experiments. PL analyzed the data and wrote the manuscript. All authors read and approved the final version of the manuscript.

\section{Ethics approval and consent to participate}

Not applicable.

\section{Patient consent for publication}

Not applicable.

\section{Competing interests}

The authors declare that they have no competing interests.

\section{References}

1. Siegel RL, Miller KD and Jemal A: Cancer statistics, 2016. CA Cancer J Clin 66: 7-30, 2016.

2. Hidalgo M: Pancreatic cancer. N Engl J Med 362: 1605-1617, 2010.

3. Humphris JL, Johns AL, Simpson SH, Cowley MJ, Pajic M, Chang DK, Nagrial AM, Chin VT, Chantrill LA, Pinese M, et al: Clinical and pathologic features of familial pancreatic cancer. Cancer 120: 3669-3675, 2014.

4. Stan SD, Singh SV and Brand RE: Chemoprevention strategies for pancreatic cancer. Nat Rev Gastroenterol Hepatol 7: 347-356, 2010.

5. Liu P, Feng J, Sun M, Yuan W, Xiao R, Xiong J, Huang X, Xiong M, Chen W, Yu X, et al: Synergistic effects of baicalein with gemcitabine or docetaxel on the proliferation, migration and apoptosis of pancreatic cancer cells. Int J Oncol 51: 1878-1886, 2017.

6. Von Hoff DD, Ervin T, Arena FP, Chiorean EG, Infante J, Moore M, Seay T, Tjulandin SA, Ma WW, Saleh MN, et al: Increased survival in pancreatic cancer with nab-paclitaxel plus gemcitabine. N Engl J Med 369: 1691-1703, 2013.

7. Circu ML and Aw TY: Reactive oxygen species, cellular redox systems, and apoptosis. Free Radic Biol Med 48: 749-762, 2010.

8. Wang H, Ge W, Jiang W, Li D and Ju X: SRPK1siRNA suppresses K562 cell growth and induces apoptosis via the PARPcaspase3 pathway. Mol Med Rep 17: 2070-2076, 2018.

9. Liu L, Han C, Yu H, Zhu W, Cui H, Zheng L, Zhang C and Yue L: Chloroquine inhibits cell growth in human A549 lung cancer cells by blocking autophagy and inducing mitochondrialmediated apoptosis. Oncol Rep 39: 2807-2816, 2018.

10. Zhu W, Liang Q, Yang X, Yu Y, Shen X and Sun G: Combination of sorafenib and Valproic acid synergistically induces cell apoptosis and inhibits hepatocellular carcinoma growth via down-regulating notch3 and pAkt. Am J Cancer Res 7: 2503-2514, 2017.

11. Yang C, Ma X, Wang Z, Zeng X, Hu Z, Ye Z and Shen G: Curcumin induces apoptosis and protective autophagy in castration-resistant prostate cancer cells through iron chelation. Drug Des Dev Ther 11: 431-439, 2017.

12. Giordano A and Tommonaro G: Curcumin and cancer. Nutrients 5: 2376, 2019.

13. Liczbinski P, Michalowicz J and Bukowska B: Molecular mechanism of curcumin action in signaling pathways: Review of the latest research. Phytother Res 6: 1002, 2020. 
14. Valastyan S and Weinberg RA: Tumor metastasis: Molecular insights and evolving paradigms. Cell 147: 275-292, 2011.

15. Simpson CD, Anyiwe K and Schimmer AD: Anoikis resistance and tumor metastasis. Cancer Lett 272: 177-185, 2008.

16. San TT, Khaenam P, Prachayasittikul V, Sripa B, Kunkeaw N and Chan-On W: Curcumin enhances chemotherapeutic effects and suppresses ANGPTL4 in anoikis-resistant cholangiocarcinoma cells. Heliyon 6: e03255, 2020

17. Jia W, Deng F, Fu W, Hu J, Chen G, Gao X, Tan X, Li G, Liu G and Zhu S: Curcumin suppresses wilms' tumor metastasis by inhibiting RECK methylation. Biomed Pharmacother 111: 1204-1212, 2019

18. Bachmeier BE, Killian PH and Melchart D: The role of curcumin in prevention and management of metastatic disease. Int J Mol Sci 9: 1716, 2018.

19. Coker-Gurkan A, Celik M, Ugur M, Arisan ED, ObakanYerlikaya P, Durdu ZB and Palavan-Unsal N: Curcumin inhibits autocrine growth hormone-mediated invasion and metastasis by targeting NF- $\kappa \mathrm{B}$ signaling and polyamine metabolism in breast cancer cells. Amino Acids 50: 1045-1069, 2018.

20. Yassine F, Salibi E and Gali-Muhtasib H: Overview of the formulations and analogs in the taxanes' story. Curr Med Chem 23: 4540-4558, 2016.

21. Mantripragada KC and Safran H: Optimizing initial chemotherapy for metastatic pancreatic cancer. Future Oncol 12 $1125-1133,2016$

22. Azimi H, Khakshur AA, Abdollahi M and Rahimi R: Potential new pharmacological agents derived from medicinal plants for the treatment of pancreatic cancer. Pancreas 44: 11-15, 2015.

23. Bar-Sela G, Epelbaum R and Schaffer M: Curcumin as an anti-cancer agent: Review of the gap between basic and clinical applications. Curr Med Chem 17: 190-197, 2010.

24. Devassy JG, Nwachukwu ID and Jones PJ: Curcumin and cancer: Barriers to obtaining a health claim. Nutr Rev 73: 155-165, 2015.

25. Hosseini M, Hassanian SM, Mohammadzadeh E, ShahidSales S Maftouh M, Fayazbakhsh H, Khazaei M and Avan A: Therapeutic potential of curcumin in treatment of pancreatic cancer: Current status and future perspectives. J Cell Biochem 118: 1634-1638, 2017.

26. Diaz Osterman CJ, Gonda A, Stiff T, Sigaran U, Valenzuela MM, Bennit HR, Moyron RB, Khan S and Wall NR: Curcumin induces pancreatic adenocarcinoma cell death via reduction of the inhibitors of apoptosis. Pancreas 45: 101-109, 2016.

27. Zhou X, Su J, Feng S, Wang L, Yin X, Yan J and Wang Z: Antitumor activity of curcumin is involved in down-regulation of YAP/TAZ expression in pancreatic cancer cells. Oncotarget 7 : 79076-79088, 2016.
28. Su J, Zhou X, Yin X, Wang L, Zhao Z, Hou Y, Zheng N, Xia J and Wang $Z$ : The effects of curcumin on proliferation, apoptosis, invasion, and NEDD4 expression in pancreatic cancer. Biochem Pharmacol 140: 28-40, 2017.

29. Youns M and Fathy GM: Upregulation of extrinsic apoptotic pathway in curcumin-mediated antiproliferative effect on human pancreatic carcinogenesis. J Cell Biochem 114: 2654-2665, 2013.

30. Fujioka S, Sclabas GM, Schmidt C, Frederick WA, Dong QG, Abbruzzese JL, Evans DB, Baker C and Chiao PJ: Function of nuclear factor kappaB in pancreatic cancer metastasis. Clin Cancer Res 9: 346-354, 2003.

31. Aggarwal BB: Nuclear factor-kappaB: The enemy within. Cancer Cell 6: 203-208, 2004

32. Wang X, Yousefi S and Simon HU: Necroptosis and neutrophil-associated disorders. Cell Death Dis 9: 111, 2018.

33. Zhang Y, Chen X, Gueydan C and Han J: Plasma membrane changes during programmed cell deaths. Cell Res 28: 9-21, 2018.

34. Yoon S, Kovalenko A, Bogdanov K and Wallach D: MLKL, the protein that mediates necroptosis, also regulates endosomal trafficking and extracellular vesicle generation. Immunity 47: 51-65, 2017.

35. Weinlich R, Oberst A, Beere HM and Green DR: Necroptosis in development, inflammation and disease. Nat Rev Mol Cell Biol 18: 127-136, 2017.

36. Wang Q, Qu C, Xie F, Chen L, Liu L, Liang X, Wu X, Wang P and Meng Z: Curcumin suppresses epithelial-to-mesenchymal transition and metastasis of pancreatic cancer cells by inhibiting cancer-associated fibroblasts. Am J Cancer Res 7: 125-133, 2017.

37. Polyak K and Weinberg RA: Transitions between epithelial and mesenchymal states: Acquisition of malignant and stem cell traits. Nat Rev Cancer 9: 265-273, 2009.

38. Bhatia S, Wang P, Toh A and Thompson EW: New insights into the role of phenotypic plasticity and EMT in driving cancer progression. Front Mol Biosci 7: 71, 2020.

39. Yilmaz M and Christofori G: EMT, the cytoskeleton, and cancer cell invasion. Cancer Metastasis Rev 28: 15-33, 2009.

40. Yoshida K, Toden S, Ravindranathan P, Han H and Goel A: Curcumin sensitizes pancreatic cancer cells to gemcitabine by attenuating PRC2 subunit EZH2, and the lncRNA PVT1 expression. Carcinogenesis 38: 1036-1046, 2017.

This work is licensed under a Creative Common Attribution-NonCommercial-NoDerivatives 4.0 International (CC BY-NC-ND 4.0) License. 